\title{
STUDYOFEFFICACYOFCOMBINATIONOFDEXAMETHASONE AND ONDANSETRON VERSUS ONDANSETRON ALONE USING SAMBA GUIDELINES FOR POSTOPERATIVE NAUSEA AND VOMITING IN LAPAROSCOPIC CHOLECYSTECTOMY.
}

\footnotetext{
1. MBBS, FCPS (Anesthesia) Graded Anesthetist CMH Gilgit.

2. MBBS, FCPS (Anesthesia), M.Sc Pain

Senior Registrar Holy Family Hospital Rawalpindi.

3. MBBS, FCPS (Anesthesia) Classified Anesthetist $\mathrm{CMH}$ Gilgit.
}

Correspondence Address:

Dr. Abeera Zareen

Senior Registrar

Holy Family Hospital Rawalpindi.

abeerajsk@gmail.com

Article received on: 31/07/2019

Accepted for publication: 25/01/2020

\begin{abstract}
Ali Arslan Munir ${ }^{1}$, Abeera Zareen ${ }^{2}$, Sumbal Rana ${ }^{3}$
ABSTRACT... Objectives: Comparing the effectiveness of combining ondansetron and dexamethasone vs ondansetron unaided in amounts suggested by SAMBA strategies for stoppage of post-operative nausea and vomiting in laparoscopic cholecystectomy patients. Study Design: Randomized Control trial. Setting: Department of Anaesthesia, Combined Military Hospital, Rawalpindi. Period: Six months (April 2015-October 2015). Material \& Methods: A sum of 160 patients were experimented by taking 80 in every group. Group A: of ondansetron. Group B: ondansetron plus dexamethasone. Significance level: $5 \%$ Test power: $80 \%$ Proportion of the projected population A is $72 \%{ }^{1}$. Foreseen population percentage $B$ is $88 \%{ }^{1}$. Besides successive non-probability specimen system was taken for sample gathering. Patients who were selected were American society of anesthesiologists $1 \& 2$ while ones with struggle in communiqué e.g. psychologic issues, memory loss, loss of speech etc, pregnant and menstruating ladies ${ }^{3}$, known of PONV, motion disease, ear problems and vertigo, on long term steroid $u^{3} e^{3}$, anguished from diabetes mellitus, hiatal hernia were excluded. The frequency of side effects were duly scribed down and doses of drugs wrote down. Rescue anti vomiting was secondhand for ones of PONV. Results: We deduced that mixture of ondansetron \& dexamethasone was effectual in averting post-operative nausea \& vomiting equated to Ondansetron unaided. Conclusion: There is variance in incidence of PONV in mutual clusters with combination remedy of ondansetron plus dexamethasone being safer as equated to Ondansetron unaided.
\end{abstract}

Key words: Dexamethasone, Laparoscopic Cholecystectomy, Ondansetron, Postoperative Nausea, Vomiting.

Article Citation: Munir AA, Zareen A, Rana S. Study of efficacy of combination of dexamethasone and ondansetron versus ondansetron alone using SAMBA guidelines for postoperative nausea and vomiting in laparoscopic cholecystectomy. Professional Med J 2020; 27(9):1839-1844.

DOI: 10.29309/TPMJ/2020.27.09.3993

\section{INTRODUCTION}

Postoperative nausea and vomiting (PONV) is a chief delinquent for subjects enduring GA and is a tense sign for patient subsequent to operations..$^{1,2}$ "In the face of the initiation of new anti-emetic drugs, short-acting anesthetics and minimal invasive surgical techniques, the prevalence of PONV has been largely unmoved and remains a major root for morbidity". ${ }^{3}$ PONV ensues in roughly $30 \%$ or more of the general surgical populace if no treatment given and up to $70 \%$ to $80 \%$ in high risk patients. ${ }^{4}$

These patients present with grave difficulties such as "aspiration, electrolyte instabilities, dehydration and disruption of incision site and have the most disagreeable experiences connected with surgery and meagre fulfilment". ${ }^{5}$ To other side it leads to growth in cost of treatment, and unexpected hospital admission as well as prolong hospital stay. ${ }^{6}$

Laparoscopic techniques have rapidly gained acceptance and have become the gold standard for cholelithiasis. High incidence of postoperative nausea and vomiting in these patients is due to pneumoperitoneum with pressurized $\mathrm{CO}_{2}$, and peritoneal manipulation. ${ }^{6}$

Current medical exercise requires by using a blend of antiemetic acting after multiple radio sites so as to reduce typically the risk of PONV 
inside high-risk patients. ${ }^{7}$ Dexamethasone for your prevention of nausea in addition to vomiting is well-known suitable. It has a half-life of around 3 hours. The first line regarding PONV management are 5-hydroxytryptamine-3 (5-HT3) receptor antagonists. Between the available drugs with this class; ondansetron is typically the most traditionally used for PONV prophylaxis. ${ }^{8}$

Other scientific studies have displayed that dexamethasone reduces PONV after laparoscopic cholecystectomy. ${ }^{11}$ The pooled meta-analysis of 7 RCTs advised that there were zero important dissimilarities between dexamethasone and ondansetron in the particular matter of the occurrence of PONV or postoperative anti-emetics used during the particular first $24 \mathrm{~h}$ right after laparoscopic surgery. Ondansetron has been batter at decreasing PONV inside the early stages postoperatively (0-6 h), while dexamethasone was more effective at reducing PONV inside the later postoperative stages (6-24 h). ${ }^{4}$

To reduce postoperative severe morbidity and mortality in addition patient costs along with regards to longer medical center stay plus treatment consequently, it can be very important that will post-operative nausea and throwing up become handled to make sure that the linked difficulties may be prevented. In this manner the particular patient discomfort, problem on hospital inpatient sections and healthcare staff could be minimized.

So far simply no study has been carried out in Pakistan to set up a highly effective antinausea and antiemetic regime for patients going through laparoscopic cholecystectomy in dosages recommended by SAMBA suggestions. Therefore rationale with this examine is to establish an efficient regime for PONV to be able to a day care surgical procedure using $4 \mathrm{mg}$ dose regarding dexamethasone as recommended by simply SAMBA.

\section{MATERIAL \& METHODS}

This study was performed at Department of Anaesthesia, Combined Military Hospital,
Rawalpindi. It was a randomized manipulated ensure that the duration related with the study had been 6 months (April 2015: October 2015). In which often usually a total regarding one hundred sixty subjects were observed merely by using 80 patients within each and every group. Group A: ondansetron group. Group B: ondansetron plus dexamethasone team. The sample size continues to be determined by using test size calculator subsequent would be the calculations: Degree of significance: $5 \%$ power of test: $80 \%$ Expected population percentage A will be $72 \%{ }^{1}$ Anticipated population percentage $B$ is $88 \% .{ }^{1} \mathrm{~A}$ great deal more over consecutive non-probability sample technique was utilized pertaining to sample collection. Individuals together with ASA-I (normal healthful patient), II (mild systemic illness with no practical limitation), Age ranged 20-45 many years and optional surgical methods were incorporated while individuals with trouble conversation e. g. psychiatric sickness, dementia, aphasia and so on, expecting and menstruating women, ${ }^{3}$ individuals with history associated with PONV, motion sickness, hearing illnesses and vertigo, upon persistent steroid therapy ${ }^{3}$, Patients struggling from diabetes mellitus, hepatic and stomach diseases, good adverse reaction or allergy to dexamethasone or ondansetron were excluded. Following approval from hospital ethics board, patients were hired according to above pointed selection criteria. Patients have been allocated to two groupings A or B, applying computer generated random numbers. All patients were examined a day before surgical procedure and written informed permission was taken.

A Group received ondansetron while team $B$ received the mix of ondansetron and dexamethasone. Zero premedication was given in addition to both group of individuals were kept nil orally (NPO) from midnight. Inside operation theater, patients that belong to group $A$ acquired ondansetron $4 \mathrm{mg}$ intravenous, whilst group $B$ received ondansetron $4 \mathrm{mg}$ with dexamethasone $4 \mathrm{mg} \mathrm{IV}$, one minute prior to induction. Right after pre-oxygenation with 100\% $\mathrm{O} 2$, both groups received pain killer nalbuphine 
(0. $1 \mathrm{mg} / \mathrm{kg}) .^{4}$ Anaesthesia was induced together with propofol $(2 \mathrm{mg} / \mathrm{kg})$ and atracurium $(0$. $5 \mathrm{mg} / \mathrm{kg}$ ) and orotracheal intubation was done. Intraoperative muscle relaxation was gained with incremental doses regarding $(0.10 \mathrm{mg} / \mathrm{kg})$ as each requirement. Anesthesia was taken care of with isoflurane and air (40\%). At the conclusion of surgery, residual neuromuscular blockade was reversed by providing neostigmine $(0.05 \mathrm{mg} / \mathrm{kg})$ mixed with glycopyrrolate $(0.01 \mathrm{mg} / \mathrm{kg})$.

Subjects were shifted to post anesthesia casre unit where they have been observed for PONV and requirement of rescue antiemetic with regard to 08 hours. Metocloperamide ten mg IV was provided for nausea persisting even more than 15 minutes or episode of vomiting.

\section{RESULTS}

A total of 160 patients were involved in the study group. The mean age of full study group was 32.42 years with standard deviation of 6.81 years. The patients in A group had a mean age $32.79 \pm$ 6.89 standard deviation. The group $B$ contained of $(n=80)$ subjects having a mean age of 31.95 $\pm 6.72(\mathrm{SD})$ years. The mean weight of complete study group consisting of both groups was 62.16 \pm 8.34 (SD) kg. The patients in group A were having a mean weight of $61.11 \pm 9.08$ (SD) $\mathrm{kg}$. The patients in group B had a weight of $63.20 \pm 8.34$
(SD) $\mathrm{kg}$. The group A consisted of 42 male and 38 female patients, whereas the group $B$ consisted of 37 male and 43 female patients. Average weight of female patients in group $A(n=38)$ was 58.06 \pm 7.43 (SD) $\mathrm{kg}$. The female patients in group $B$ $(n=43)$ had a mean weight of $62.53 \pm 7.35$ (SD). Out of 80 patients in group A, 47 were classified as ASA-I and 33 were classified as ASA-II. In the group B, 45 patients were classified as ASA-I and 35 were classified as ASA-Il. Thus, the total population of $n=160$ composed of 92 ASA-I and 68 ASA-II patients. The detailed demographics of the study population are explained in Table-l.

Occurrence of Nausea and vomiting was documented in both groups throughout the first 08 hours of post-surgery period. Overall nearly 44 $\%(n=70)$ of the subjects in the population did not feel any nausea or vomiting. In total population, 90 out of 160 patients went through nausea and vomiting. The prevalence is shown in Figure-1.

93.75\% in Group A experienced bouts of nausea and vomiting , instead $6.25 \%$ patients did not suffer any nausea or vomiting. In group B, $18.75 \%$ $(n=15)$ patients suffered nausea and vomiting while $81.25 \%(n=65)$ patients did not. Chi-square test was used and p-value was gauged to be 0.000 , which is well below 0.05 . The outcome of treatment is tabulated in Tables-II.

\begin{tabular}{|l|c|c|c|c|c|c|}
\hline & \multicolumn{3}{|c|}{ Group A } & \multicolumn{3}{c|}{ Group B } \\
\hline & Male & Female & Total & Male & Female & Total \\
\hline Number & 42 & 38 & 80 & 37 & 43 & 80 \\
\hline Age & $33.49 \pm 6.83$ & $32.42 \pm 6.98$ & $32.79 \pm 6.89$ & $32.08 \pm 7.32$ & $32.02 \pm 6.35$ & $32.05 \pm 6.92$ \\
\hline Height & $170.7 \pm 13.7$ & $152.6 \pm 13.8$ & $166.0 \pm 14.2$ & $163.7 \pm 10.9$ & $159.8 \pm 14.4$ & $161.6 \pm 13.2$ \\
\hline Weight & $63.81 \pm 9.96$ & $63.97 \pm 7.44$ & $63.84 \pm 8.72$ & $58.06 \pm 7.43$ & $62.53 \pm 7.35$ & $60.52 \pm 7.60$ \\
\hline & \multicolumn{3}{|c|}{ Table-l. Group wise demography of the study Population. } \\
\hline
\end{tabular}

\begin{tabular}{|c|c|c|c|}
\hline \multirow{2}{*}{ Effectiveness } & \multicolumn{2}{|c|}{ Treatment Given } & P-Value \\
\hline Yes & Ondansetron (Group A) & $\begin{array}{c}\text { Ondansetron Plus Dexamethasone } \\
\text { (Group B) }\end{array}$ & \multirow{2}{*}{0.000} \\
\hline No & $5(6.25 \%)$ & $65(81.25 \%)$ & $15(18.75 \%)$ \\
\hline Total & $75(93.75 \%)$ & $80(100 \%)$ & \\
& $80(100 \%)$ & Table-II. PONV frequency and percentages after treatment in both groups. \\
\hline
\end{tabular}




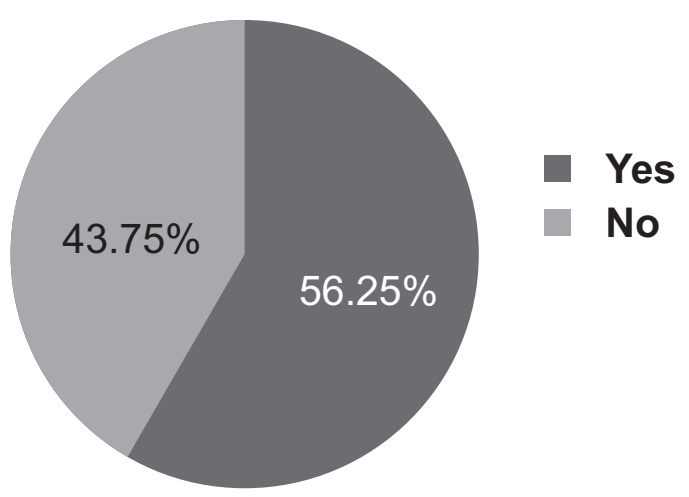

Figure-1. Overall incidence of PONV.

\section{DISCUSSION}

There was no significant difference in age and gender distribution of two groups.

\section{PONV in the Study Group}

Surgical Procedures like Laparoscopic Cholecystectomy are associated with high incidence of Post-operative Nausea and vomiting if no pharmacological prophylaxis is used. During the first 08 hours of post-operative period the incidence of nausea and vomiting was around $56 \%$ in our study group. In other words only 44 $\%$ of the patients were without any nausea and vomiting during eight hours when antiemetic prophylaxis was given either by Ondansetron plus dexamethasone or Ondansetron.

In study conducted by $\mathrm{Li} \mathrm{ZH}$ et al there were greater proportion of patients without nausea with use of dexamethasone undergoing modified radical mastectomy. ${ }^{7}$

A study was conducted at Teleghani Hospital in Arak, Iran comparing prophylactic antiemetic therapy with Ondansetron, haloperidol and dexmedetomidine in patients undergoing laparoscopic hysterectectomy. It was observed that Prophylactic antiemetic treatment with Ondansetron resulted in a lower incidence $(P=$ $0.04, P=0.02, P=0.001$ ) of PONV than with other two groups. The times at which rescue antiemetic was first received were longer $(P<$ 0.01) in Ondansetron group than in other two groups. Kamali A et al, in the study concluded that Ondansetron, when given prophylactically resulted in a significantly lower incidence of PONV than Haloperidol and dexmedetomidine. ${ }^{8}$

Similar findings were found in a recent study conducted by University of Miami-Jackson Memorial Hospital, USA in which he noted that prophylaxis using Ondansetron and palonsetron have comparable in efficacy when used in prophyxais against PONV. ${ }^{9}$

Role of Dexamethasone to decrease postoperative nausea and vomiting was assessed by Seki $\mathrm{H}$. This was a study on how does dexamethasone influence surgical outcome after correction of idiopathic scoliosis. During this randomized double-blind placebo-controlled trial 44 patients were randomized to receive dexamethasone $(8 \mathrm{mg})$ intravenously or saline (placebo). It was observed that 4 out of 11 (36\%) who received dexamethasone and 26 out of $33(79 \%)$ who did not receive dexamethasone developed PONV in first 72 hours after surgery (OR 0.15 95\% Cl: 0.04-0.681, $\mathrm{P}=0.02\}$. Authors in this study concluded that Preoperative dexamethasone significantly reduce nausea and vomiting in post-operative period when compared with placebo. ${ }^{10}$

Similar conclusions have been drawn by Fujii $Y$ in his study published in surgical endoscopy during 2011. In this study at Japan he observed that antiemetic therapy combined with a serotonin receptor antagonist like Ondansetron or dexamethasone is highly effective in the prevention of PONV after Laparoscopic Cholecystectomy. ${ }^{11}$

\section{Comparison of Ondansetron alone \& Ondansetron plus Dexamethasone}

In our study each group had 80 patients in it. Among the Ondansetron group 75 patients had nausea \& vomiting while in Ondansetron plus dexamethasone group 15 patients had nausea \& vomiting. In other words $6.25 \%$ of patients $(n=5)$ in ondansetron group while $81.25 \%$ of patients $(n=65)$ in Ondansetron plus dexamethasone group were free of Nausea \& Vomiting. So patients who received ondansetron plus dexamethasone for prophylaxis had better control of Nausea \& Vomiting than patients who received Ondansetron 
alone (81.25\% vs. $6.25 \%)$.

A Study published in Surgical Anaesth Essays Res in 2018 was a randomized controlled study to compare Palonsetron and granisetron for the prevention of postoperative nausea and vomiting in patients undergoing laparoscopic abdominal surgery. During this study it was observed that the total incidence of PONV at $0-2 \mathrm{~h}$ was $15 \%$ with palonsetron and $27.5 \%$ with granisetron, The incidence of PONV at $2-24 \mathrm{~h}$ was $20 \%$ with palonsetron and $30 \%$ with granisetron \& $17.5 \%$ and $37.5 \%$ during $24-48 \mathrm{~h}$ respectively. The differences between palonsetron and granisetron, was not significant in early recovery period. Tahir S et al concluded that due to its prolonged duration of action, palonsetron was more effective than granisetron for long term prevention of PONV after laparoscopic abdominal surgery. ${ }^{12}$

In study conducted in university school of medicine, Turkey compared the effects of ondansetron - dexamethasone combination with dexamethasone-aprepitant combination for prevention of postoperative nausea and vomiting. The incidence of postoperative nausea was similar in both combinations (DO 67\%, DA $69 \%)(P=0.93)$. Bilgen $S$ et al, concluded that dexamethasone-aprepitant has not improved the complete response of PONV as compared to dexamethasone-ondansetron. ${ }^{13}$

One of the studies conducted at Department of Anesthesiology, Dow University of Health Sciences Karachi, Pakistan has compared the efficacy of combination of dexamethasone plus Ondansetron with dexamethasone alone for postoperative nausea and vomiting in patients undergoing laparoscopic cholecystectomy. This was a Double blinded randomized controlled clinical trial during March 2007 to September 2007. In this study Bano F et al observed that In comparison to dexamethasone group, the frequency ofnauseaandvomiting wasclinicallyand statistically lower in dexamethasone Ondansetron group $(p=0.035)$. Use of rescue antiemetic was significantly higher in dexamethasone group $(p=0.022)$. They concluded that Combination of dexamethasone plus Ondansetron is more effective in preventing postoperative nausea and vomiting than dexamethasone alone when used for prophylaxis of PONV before the induction of anesthesia in patients undergoing laparoscopic cholecystectomy. ${ }^{14}$

So our study results match with most of the published literature in that combination therapies like Ondansetron plus dexamethasone therapies are effective in controlling the PONV. Ondansetron plus dexamethasone has proved to be more effective than Ondansetron alone in prophylaxis of PONV when used preoperatively in patients undergoing laparoscopic cholecystectomy.

\section{CONCLUSION}

Ondansetron plus dexamethasone has proved more effective than Ondansetron alone in the prophylaxis of post-operative nausea and vomiting when used in doses recommended by SAMBA guidelines in patients undergoing laparoscopic Cholecystectomy.

\section{Acknowledgements}

This study has no conflict of interest to declare by any author.

Copyright $@ 25$ Jan, 2020.

\section{REFERENCES}

1. Ahsan K, Abbas N, Naqvi SM, Murtaza G, Tariq $S$. Comparison of efficacy of ondansetron and dexamethasone combination and ondansetron alone in preventing postoperative nausea and vomiting after laparoscopic cholecystectomy. J Pak Med Assoc. 2014 Mar; 64(3):242-6.

2. Sayed JA, F Riad MA, M Ali MO. Comparison of dexamethasone or intravenous fluids or combination of both on postoperative nausea, vomiting and pain in pediatric strabismus surgery. J Clin Anesth [Internet].2016 Nov;34:136-42. Available from https:// www.ncbi.nlm.nih.gov/pubmed/27687360 DOI: 10.1016 .

3. Benevides ML, Oliveira SS, de Aguilar-Nascimento JE. Combination of haloperidol, dexamethasone and ondansetron for prevention of postoperative nausea and vomiting in laparoscopic sleeve gastrectomy: A randomized double blind trail. Obes Surg [Internet]. 2013 Sep; 23(9):1389-96. Available from : https://www. researchgate.net/publication/236081548 DOI:10.1007/ s11695-013-0923-1. 
4. Butterworth J, Mackey D, Wasnick J, Morgan G, Mikhail M. Morgan and Mikhail's clinical anesthesiology. 6th ed. New York: McGraw Hill Education; 2018 482-3p.

5. Al-Saad SN. The timing of ondansetron administration in prevention of postoperative nausea and vomiting. A comparative study for female patients undergoing laparoscopic cholecystectomy. Iraqi Postgraduate M. 2013; 12(3):449-453.

6. Gildasio DO, Lucas CA, Shireen A, Mark KC, Robert MJ. Dexamethasone to prevent postoperative nausea and vomiting: An updated meta-analysis of randomized controlled trials. Anesth Analg [Internet]. 2013 Jan; 116(1):58-74 Available from https://www.ncbi. nlm.nih.gov/pubmed/23223115 DOI: 10.1213.

7. Li ZH, Liu D, He ZJ, Fan ZY. Influence of dexamethasone on the incidence of postoperative nausea and vomiting in breast cancer patients with neoadjuvant chemotherapy. Beijing Da Xue Xue Bao Yi Xue Ban [Internet]. 2015 Aug 18; 47(4):685-9. Available from http://europepmc.org/abstract/MED/26284410

8. Kamali A, Ahmadi L, Shokrpour M, Pazuki S. Investigation of ondansetron, haloperidol, and dexmedetomidine efficacy for prevention of postoperative nausea and vomiting in patients with abdominal hysterectomy. Maced J Med Sci [Internet]. 2018 Sep 25; 6(9):1659-1663. Available from https://doi. org/10.3889/oamjms. 2018.366.

9. Candiotti KA, Ahmed SR, Cox D, Gan TJ. Palonosetron versus ondansetron as rescue medication for postoperative nausea and vomiting: A randomized, multicenter, open-label study. BMC Pharmacol Toxicol. 2014 Aug 16; 15:45. DOI: 10.1186/2050-6511-15-45.
10. Seki $H$, Wakamiya $R$, Ihara $N$, Ideno S, Minoshima $R$, Murase $R$ et al. The effect of dexamethasone on postoperative nausea and vomiting in posterior correction and fusion surgery for adolescent idiopathic scoliosis. Masui. 2017 Mar; 66(3):298302. Available from https://www.pubfacts.com/ detail/30380222/.

11. Fujii Y, Nakayama M. Prevention of postoperative nausea and vomiting with a small dose of propofol alone and combined with dexamethasone in patients undergoing laparoscopic cholecystectomy: A prospective, randomized, double-blind study. Surg Endosc [Internet].2008 May; 22(5):1268-71. Available from https://www.ncbi.nlm.nih.gov/pubmed/18000709 DOI: $10.1007 / \mathrm{s} 00464-007-9647-4$.

12. Tahir S, Mir AA, Hameed A. Comparison of palonsetron with granisetron for prevention of postoperative nausea and vomiting undergoing laparoscopic abdominal surgery. Anaesth Essays Res [Internet]. 2018 Jul-Sep;12(3):636-43. Available from https://www. ncbi.nlm.nih.gov/pubmed/30283168 DOI: 10.4103/aer. AER_84_18.

13. Bilgen S, Kizilick N, Haliloglu M, Yildrim G, Kaspar EC, Koner $\mathrm{O}$ et al. Effect of Dexamethasone-Ondansetron combination versus Dexamethasone-Aprepitant combination to prevent of postoperative nausea and vomiting. Turk J Anaesthesiol Reanim. 2018 Sep; 46(5):373-80.

14. Bano F, Zafar S, Aftab S, Haider S. Dexamethasone plus ondansetron for prevention of postoperative nausea and vomiting in patients undergoing laparoscopic cholecystectomy: A comparison with dexamethasone alone. J Coll Physicians Surg Pak. 2008 May; 18(5):265-9.

\begin{tabular}{|c|c|c|c|}
\hline \multicolumn{4}{|c|}{ AUTHORSHIP AND CONTRIBUTION DECLARATION } \\
\hline Sr. \# & Author(s) Full Name & Contribution to the paper & Author(s) Signature \\
\hline $\begin{array}{l}1 \\
2 \\
3\end{array}$ & $\begin{array}{l}\text { Ali Arslan Munir } \\
\text { Abeera Zareen } \\
\text { Sumbal Rana }\end{array}$ & $\begin{array}{l}\text { 1st Author } \\
\text { 2nd Author } \\
\text { 3rd Author }\end{array}$ & 6 \\
\hline
\end{tabular}

